\title{
FORMAÇÃO DE LEITORES NO AMAZONAS: A RELAÇÃO ENTRE UNIVERSIDADE E MOVIMENTOS SOCIAIS
}

\author{
Marina Graziela Feldmann ${ }^{1}$ \\ Maria De Nazaré Corrêa Silva²
}

\section{INTRODUÇÃO}

O Grupo de Pesquisa Formação de Professores e Cotidiano Escolar, certificado no ano de 2000 pelo Conselho Nacional de Desenvolvimento Científico e Tecnológico (CNPq), do Programa de Pós-Graduação em Educação: Currículo da Pontifícia Universidade Católica de São Paulo tem realizado pesquisas na busca da ampliação do entendimento do que significa ser professor no mundo contemporâneo. Nesse sentido, algumas dimensões de análise são tomadas como fundantes da produção acadêmico-científica do Grupo: a valorização das experiências dos sujeitos curriculares como forma de conhecimento e a articulação entre os saberes produzidos e os fundamentos teóricos relacionados. Isso tem exigido uma problematização constante por parte de seus pesquisadores na perspectiva da vivência de uma educação contextualizada, relacional e humanizada. O princípio fulcral nessa busca pelo conhecimento consubstancia-se em compreender o fenômeno educativo como uma tarefa inconclusa e na forma fractal de interrogar o mundo. Entender dessa forma a educação acarreta, como explica Feldmann:

tomá-la em sua concretude, em sua manifestação histórica, política e social [...]. Envolve relações entre as pessoas, projetos e processos que se produzem mutuamente contraditoriamente embasados em uma visão de homem, mundo, natureza e sociedade. E ainda as pessoas se educam quando produzem a sua existência relacionada com a existência do outro, em um processo permanente de apropriação, mediação e transformação do conhecimento mediante um projeto existencial e coletivo de construção humana (FELDMANN, 2009, p. 72).

\footnotetext{
${ }^{1}$ Professora Titular do Departamento de Fundamentos da Educação da Pontifícia Universidade Católica de São Paulo. Coordenadora e Pesquisadora do Programa de Pós-Graduação em Currículo da PUC/SP. Líder do Grupo de Pesquisa Formação de Professores e Cotidiano Escolar (CNPq).feldmnn@uol.com.br

${ }^{2}$ Doutoranda do Programa de Pós-Graduação em Educação: Currículo da Pontifícia Universidade Católica de São Paulo. professoranazareuea@hotmail.com
} 
O nosso Grupo de Pesquisa tem se concentrado em estudos e pesquisas sobre o entrelaçamento da tríade formação, currículo e cultura, tomando-a como constitutiva dos sujeitos curriculares no sentido de contribuir para a construção de diálogos por entendermos o ato curricular como espaço vivo de constante formação.

Diante da complexidade em se tentar expressar uma definição de currículo, a concepção que tem norteado os nossos estudos é o de seu entendimento como:

construção social e epistemológica do conhecimento, concretizada em espaços educativos e vivenciada em movimentos de tensões e lutas pela ocupação territorial dos saberes". Nesses movimentos se mostram as delimitações dos significados dos campos de conhecimento, seus processos (discursos e métodos) e o sentido dos sentidos na vida das pessoas envolvidas (FELDMANN, 2009, p.73).

Falar de sujeitos curriculares implica em se ter como base de entendimento que nos processos de formação, a aprendizagem está sempre atrelada ao contexto em que vivemos e convivemos. Esse contexto vai para além do entendimento de um espaço físico delimitado geograficamente e se constitui também e, principalmente, pelo processo de comunicação, pelo imaginário das pessoas que com suas narrativas criam e são criados por ideias, concepções, valores e atitudes em vivências compartilhadas cotidianamente de acordo com as diversidades e interculturalidades presentes.

Assim, apresentamos as reflexões provenientes de uma pesquisa realizada por meio de um projeto de extensão do Curso de Pedagogia de uma instituição do ensino superior do estado do Amazonas que objetivava a formação de leitores em espaços alternativos na complexa relação entre a universidade e os movimentos sociais, apresentada a seguir.

\section{A ORIGEM}

A investigação ora relata a busca por tornar conhecidas experiências que ocorrem por esse Brasil a fora por pessoas, instituições e movimentos sociais que pensam a partir de viés contra hegemônico. Foram registradas as principais referências das ações tais como: a origem, a metodologia utilizada, os atores sociais envolvidos, tempos e espaços vivenciados e literatura eleita. As obras disponíveis foram selecionadas a partir de autores locais e retratavam genuinamente o universo caboclo, sendo assim consideradas de fácil compreensão e reflexão por parte de todos, apesar do sofisticado estilo de uma delas como foi o caso de Sol de Feira. 
Portanto, este trabalho apresenta, no primeiro momento, a origem do projeto e a seleção da literatura usada pelos mediadores da ação, fruto de uma análise documental, com destaque para os relatórios e artigos apresentados em eventos científicos. Ouviu-se, relatos e narrativas disponíveis na Pró-Reitoria de Extensão e Assuntos Comunitários da instituição provedora e em locais de residência e ou militância dos grupos que vivenciaram a experiência. As considerações deste trabalho foram inconclusas a exemplo do permanente movimento dos atores sociais ao perseguirem a sonhada emancipação. Este artigo conta com os seguintes tópicos: Conhecendo a origem e as obras literárias eleitas, a diversidade cultural dos movimentos sociais, as intenções das formações e seu viés metodológico, locais e períodos da ação formativa e, caracterização dos atores.

A iniciativa do projeto foi de um grupo de professores e alunos do Curso de Pedagogia após receber propostas dos movimentos sociais locais que contemplassem ações desta natureza. A relação da universidade com os sujeitos da ação se deu em quatro movimentos que se constituíram como chaves no processo. A sistematização da ideia trazida pelos movimentos, a organização e seleção da equipe e das obras literárias, a formação dos mediadores de leitura e os encontros com os grupos contemplados. As formações dos acadêmicos/bolsistas e voluntários se transformavam na multiplicação da formação dos sujeitos alfabetizados recentemente estabelecendo com esses o fazer e o saber reflexivo da ação. O projeto usava um "paneiro" itinerante no qual os livros iam sendo depositados e disponibilizados nos momentos de estudo, por isso, ficou conhecido como Paneiroteca. Os integrantes elegeram três obras da literatura amazonense com as quais, mas se identificaram em suas histórias de vida. Os títulos da literatura escolhida foram: A Caligrafia de Deus de Marcio Souza (2008), Sol de Feira de Luiz Bacellar (2009) e Os Estatutos do Homem de Thiago de Melo (2009). Essas obras faziam parte do acervo de mais de oito mil exemplares doados por uma editora local parceira do projeto e tiveram edição especial destinado há uma semana literária denominada FLIFLORESTA no ano anterior.

\section{SOBRE AS OBRAS ELEITAS E SUAS AUTORIAS:}

O Romance de Souza (2008) A Caligrafia de Deus, utilizada no projeto, é composta de três contos. O primeiro que leva o nome do romance, o segundo No Fim da Tarde, Antes do Jantar e o terceiro, Aquele pobre Diabo.

Para Santelli, 
de nossos olhos. Poderíamos comparar o percurso da índia Izabel, personagem do primeiro conto, uma adolescente que sai de seu habitat e vai para a cidade grande, aqui uma Manaus em transformação urbana aguda. A transformação física violenta é a única regra possível para esta personagem, a única alternativa restante para quem deseja sobreviver num mundo amazônico, onde a religião dita as regras. Estas personagens são estranhas para si mesmas, suas identidades são perdidas, isto é, arrancadas no caminho, ou melhor, dito: forjadas. (SANTELLI, 2008, p.1)

Márcio Souza, por meio de uma de suas passagens do conto Aquele pobre diabo diz:

Na popa, ele pegou mais uma dose de cachaça e levantou os olhos para a escadaria que se elevava das águas negras do rio e desaparecia na noite sem estrelas. O chão era de tábuas largas, escuras, muito lisas e enceradas pelo pisar de muitos pés descalços... Um barco comum, artesanato naval local. Ele pensava sobre isso: o barco. Mas também sobre o rio. (SOUZA, 2008, p. 55)

O interessante nos encontros era que não só os recém-alfabetizados, mas também os mediadores de leitura se viam nos personagens e contextos narrados pelos autores.

Luiz Bacellar (2009), autor de Sol de Feira.

Se o Brasil não fosse um arquipélago cultural, todos certamente conheceriam a poesia de Luiz Bacellar... Sol de Feira" é dos seus livros o mais querido e mais popular, apesar do rigor da forma (rondel), da linguagem erudita e da temática, que remonta aos pomulários góticos da França e a certa poesia que se praticou no Brasil Colônia entre 1650 e 1750. Ao escrever Sol de Feira o poeta o fez com a intenção de servir de textos para uma suíte de danças brasileiras. O crítico literário Marcos Frederico Kroger se refere a Sol de Feira como poesia sol, confeccionada com água, matemática e sonhos.http://www.saraiva.com.br/sol de feira-2639058 html.

A escolha da obra Sol de Feira foi feita pelo grupo indígena por encontrarem as frutas aludidas pelo autor vivas e robustas em seu território como ilustra o rondel a abaixo:

\section{Rondel do Tucumã}

Do teu minúsculo coquinho relatam lendas milenárias brotaram sono, amor, Carinho, a lua e as outras luminárias; onças e pássaros noturnos, quando em teu bojo se escondia dele fugiu com ares soturnos enquanto o breu se derretia; tu foste à caixa de Pandora das tribos bárbaras de outrora e a cor das asas da graúna saiu de ti como um trovão para que a filha da boiuna pudesse amar na escuridão... 


\section{(Http://historiadosamantes.blogspot.com.br)}

Dessa forma, os integrantes sentiram-se desafiados a contar sua própria história escolhendo o gênero que melhor lhes provia.

Planejar atividades de incentivo à leitura tem sido um dos objetivos perseguidos pelas instituições escolares e educadores. Normalmente, são criados clubes de leitura para despertar nos alunos o gosto pelos livros, mostras literárias com pesquisas sobre obras de grandes autores da literatura brasileira, saraus de poesias, rodas de história com diferentes gêneros textuais, entre outras. Mas será que essas atividades são suficientes para garantir que nossos leitores em formação possam interpretar e compreender de forma autônoma textos escritos? Como recriar momentos de leitura a partir de uma prática cultural, política e pedagógica de sujeitos preocupados com seu tempo e compromissados com os interesses populares?

Essas foram algumas das preocupações que o projeto de extensão teve com a perspectiva de fomentar o prazer pela leitura. Nesse contexto, o grupo organizador definiu que seria preciso que ela fosse vista e sentida, como uma atividade cultural, intencional e relacional e, sobretudo, como um ato de vincular linguagem e realidade, e não apenas uma manipulação mecânica de palavras. Observamos que o projeto foi capaz de mobilizar o leitor e o fazer assumir uma posição ativa diante do texto, mesmo antes de lerem e escreverem convencionalmente. Freire chamou a isso de "atitude frente ao mundo". É preciso conceber a leitura como instrumento de inserção social dos jovens, adultos ou idosos, formando um novo homem, capaz de ler, para além das palavras, o próprio mundo, como nos ensina Paulo Freire. Os neoleitores, parafraseando esse grande educador, devem entender o que leem, conseguindo depois escrever o que entendem. Entender o que está além das palavras contribui para tornar essas pessoas seres no mundo e com o mundo, resgatando seu papel de sujeitos e não de meros e permanentes objetos Freire, (1989).

\section{A CULTURA DOS MOVIMENTOS SOCIAIS}

Aprendemos com Baumann (1999), que havia duas visões de cultura disponíveis, na época em que, o modelo ortodoxo de cultura, se tornou predominante. A visão dos de dentro com a dos de fora, ambas necessárias para que se pudesse evocar a visão de sistema. Depreende-se disso que, para atender aos critérios da sistematicidade, o conjunto de itens precisa ser circunscrito, ou seja, deve ter fronteiras. Para os de fora recém-chegados, que passam a integrar o sistema, devem se "ajustar" permitindo que o sistema os assimile, sendo essa assimilação uma via de mão única. Para os recém- 
chegados, assimilação significa transformação, enquanto para o sistema significa reafirmação de sua identidade.

Diante dessa situação e em busca de novas perspectivas, ressalta-se aqui a experiência de Malinowski, antropólogo que é responsável por criar essa concepção de produção cultural, como recorda Baumann (1999). Segundo informa sua obra, Malinowski visitou as "populações nativas" com um modo de vida claro, distinto do seu. Imergiu no seu cotidiano e registrou tudo, para daí "extrair um sentido", encaixando cada um dos hábitos ou ritos observados, numa totalidade abrangente de rotinas que supostamente, tornam o modo de vida investigado viável e capaz de se autoperpetuar.

De um lado, a literatura consultada no projeto apontou para a existência de várias áreas do globo incomunicáveis ou com comunicação reduzida com as áreas vizinhas, consideradas por Baumann, como totalidades fechadas. Por outro, havia Estados nação que promoviam, de modo explícito e forçado, a unificação nacional de línguas, calendários, padrões de educação, versões da história e códigos de éticos juridicamente fundamentados- Estados preocupados em homogeneizar o vago conjunto de dialetos, costumes e memórias coletivas locais para formar um conjunto único comum, nacional, de crenças e estilos de vida.

Era natural aos exploradores culturais da época presumir que todas as populações devessem se preocupar com os problemas conhecidos a partir das práticas domésticas dos próprios exploradores. Afirma o autor que também é natural para nós, duvidar das "totalidades" semelhantes a sistemas invocados pela antropologia cultural ortodoxa. Fica a dúvida, se as culturas exploradas era uma ilusão de ótica ou uma percepção adequada de uma realidade agora distante. Reflete ainda,

\footnotetext{
[...]que qualquer que tenha sido o caso, essa imagem se choca de modo estridente com nossa experiência atual de símbolos culturais que flutuam livremente; da porosidade das fronteiras que algumas pessoas gostariam de fechar, embora não sejam capazes; e de governos de Estado que promovem ativamente o "multiculturalismo", não mais interessados em privilegiar algum modelo particular de cultura nacional, mas preocupados em não infringir qualquer das incontestáveis "opções culturais" individual ou coletivamente assumidas (BAUMANN, 199, p. $31)$.
}

De posse desses princípios e, constatado o baixo grau de alfabetismo dos demandantes da ação, provenientes de setores excluídos e residentes nas periferias dos centros urbanos e comunidades indígenas, o projeto traçou o perfil dos mediadores de leitura e reconheceu ainda, que não basta superar o analfabetismo, é necessário romper com uma questão histórica que contribuiu com o 
aprofundamento das desigualdades sociais que é a exclusão. Para tanto, foram desenhadas ações para possibilitar que fosse garantida a esses sujeitos a possibilidade de ler o mundo de forma reflexiva e crítica, compreendendo seu papel de sujeitos na sociedade e de intervenção na mesma. A compreensão da realidade, no entanto, só é possível se esses sujeitos tiverem condições motivacionais e sociais de darem continuidade a sua escolarização e/ou, desenvolverem suas habilidades de leitura e escrita intervindas em seus territórios.

No âmbito das conquistas, a exigência de políticas afirmativas para essas situações dá-se fundamentalmente pela estatística que expõe a privação do direito à educação escolar de grupos socialmente excluídos. Políticas essas que, segundo seus defensores, ainda não lograram ações proporcionais à magnitude do problema, como se pode observar por meio dos seguintes dados:

A taxa de analfabetismo da população de 15 anos ou mais que apresenta um patamar de 23,3\% na área rural, três vezes superior àquela da zona urbana, que se encontra em 7,7\%; a escolaridade média da população 15 anos ou mais que vive na zona rural, que é de 4,5 anos, enquanto, no meio urbano, na mesma faixa etária, é de 7,8 anos; as condições de funcionamento das escolas de ensino fundamental, que são extremamente precárias, pois $75 \%$ dos alunos são atendidos em escolas que não dispõem de bibliotecas; $98 \%$ em escolas que não possuem laboratório de ciências; e 92\% em escolas que não possuem acesso à internet (MOLINA et al, apud, CALDART, 2012, p. 455).

Silva (2012) reconhece que a necessidade de atender aos anseios dessa parcela da sociedade representada pelos grupos contemplados tornou-se imperativa, haja vista, a carência de bibliotecas comunitárias na região. O que existia na verdade eram algumas bibliotecas nas redes de escolas municipais e estaduais com atendimento restrito aos alunos com efetiva matrícula. Essa situação acentua-se ainda mais quando se estende, sobretudo, aos residentes na zona rural, aos povos tradicionais indígenas e não indígenas iletrados em vulnerabilidade social: ribeirinhos e indígenas, distribuídos em milhares de localidades rurais de difícil acesso, com distâncias que variam em horas a dias de deslocamento até a sede do município. Registra-se que o difícil acesso decorre de fatores geográficos, incidindo de forma a dificultar as oportunidades educacionais desse público. Contudo, não o vemos dissociado da ausência de condições objetivas decorrentes de aspectos socioeconômicos para o desenvolvimento regional. $\mathrm{O}$ ensino fundamental não garante o acesso a todos os que precisam e, a necessidade de sobrevivência e de provimento de seu sustento contribui significativamente para que muitos desses educandos evadam-se logo nas séries iniciais. 
Outro aspecto importante é que alguns mediadores achavam que bastava apresentar textos variados para garantir a funcionalidade da leitura. No entanto, durante as formações e com as intervenções perceberam a necessidade de elaborar situações propícias a reflexões nas quais, os sujeitos, compreendessem as diferenças estruturais e regularidades discursivas que caracterizam cada texto. Dessa forma, mostra-se importante registrar que a segurança se fortaleceu quando a experiência foi replicada em outros municípios. Silva (2014) relata que:

Em Parintins, Baixo Amazonas com o projeto Tricicloteca: uma viagem de leitura do povo ribeirinho as margens do Rio Amazonas, oportunizou a este público, uma biblioteca comunitária por meio da distribuição de livros em triciclos, transporte adaptado em uma bicicleta e fixado no porto do local. Este projeto foi desenvolvido em uma balsa que fazia o transporte das pessoas de Parintins ao vilarejo de Vila Amazônia. Durante o trajeto as pessoas tiveram a oportunidade não só de acesso a livros, como também de interagirem entre si, por meio do relato de "causos", lendas e mitologia da região. Outra experiência relatada foi a do Município de Carauari, localizado no Rio Juruá, onde, a secretaria de Educação fez uma articulação com o projeto de leitura denominado Expedição Vaga-lume. Neste projeto, havia um momento destinado ao intercâmbio entre jovens e idosos que se dava através da "contação" de histórias por parte dos mais velhos aos mais jovens e da leitura de livros pelos jovens já alfabetizados (SILVA, 2014, p.10).

A construção dessa ação de leitura, com suas especificidades no que diz respeito à relação de produção de conhecimento e de inovações na organização do trabalho pedagógico, seguiu orientação das lutas populares, que recomendam fazer-se "acompanhar das diretrizes pelas exigências de formação de educadores próprios para o exercício da função docente, tal como exigem os movimentos sociais presentes na Daobec de 2002" (CALDART, 2012, p. 454).

\section{AS INTENÇÕES DAS FORMAÇÕES E SEU VIÉS TEÓRICO-METODOLÓGICO}

O objetivo geral do projeto foi desenvolver formações que garantissem efetivamente a apropriação das ferramentas indispensáveis ao uso competente de práticas sociais de leitura a partir da literatura regional contribuindo para a continuidade do ato educativo e fortalecimento do aprendizado dos sujeitos aprendizes, inclusive, dos acadêmicos, líderes comunitários e docentes da equipe. Para tanto, foi necessário garantir espaços de leitura, intercâmbio entre os diversos ambientes educacionais e culturais, preparo dos profissionais para realizarem ações de mediação de leitura, realização de formas diversificadas de encontros que priorizassem o tema da leitura, promoção e utilização de estratégias que lhes permitissem interpretar e compreender autonomamente os textos 
escritos, suscitação da necessidade de ler ajudando a autorreflexão e, por conseguinte, descobrirem as diversas utilidades da leitura em situações de aprendizagem significativa. Por fim, favorecer a transformação dos integrantes em leitores ativos para que assumisse responsabilidade ante o ato de ler garantindo assim, a construção de uma interpretação sobre os textos necessários para a resolução dos problemas que surgiram no decorrer da atividade de leitura.

As preocupações de Garcia (1999), em cuidar dos diferentes olhares sobre a formação foi uma referência conceitual para analisar o projeto. Em sua obra "Formação de Professores para uma Mudança Educativa", apresenta um leque de visões sobre a temática contemplando distintas fases caracterizadas, inclusive, como pré-treino, formação inicial, fase de iniciação e de formação permanente. Por fim conceitua:

\begin{abstract}
A Formação de Professores é a área de conhecimento, investigação e de propostas teóricas e práticas que, no âmbito da Didática e da Organização Escolar, estuda os processos através dos quais os professores em formação ou em exercício, se implicam individualmente ou em equipe, em experiências de aprendizagem através das quais adquirem ou melhoram os seus conhecimentos, competências e disposições, e que lhes permite intervir profissionalmente no desenvolvimento do seu ensino, do currículo e da escola, com o objetivo de melhorar a qualidade da educação que os alunos recebem (GARCIA, 1999, p. 26).
\end{abstract}

O autor concebe a formação inicial, como espaço no qual professores, gestores e atores sociais compõem o fenômeno educativo enquanto tarefa inconclusa, inacabada, tal qual foi percebido na análise em foco. A formação continuada, também envolvendo professores e gestores deve se articular aos afazeres na e da escola em um todo compartilhado.

Feldmann (2009 p.78) nos diz que a” escola ou o espaço educativo passa a ser um espaço constitutivo do professor, nela se faz e refaz a identidades pessoal e profissional que por sua vez, também é construída por uma série de símbolos existentes no cotidiano da escola. Este espaço se constitui num entrecruzamento de diferentes culturas.

Para Garcia, vários autores renomados reforçam esse pensamento dizendo: "A Formação de Professores representa uma das pedras angulares imprescindíveis em qualquer tentativa de renovação do sistema educativo" (GIMENO SACRISTÁN (1982, p.77 apud GARCIA, 1999, p. 23).

O autor continua a explicação sobre formação, expondo que: 
Consideramos a formação de professores como a preparação e emancipação profissional do docente para realizar crítica, reflexiva e eficazmente um estilo de ensino que promova uma aprendizagem significativa nos alunos e consiga um pensamento-ação inovador, trabalhando em equipe com os colegas para desenvolver um projecto educativo comum" (MEDINA e DOMINGUEZ, 1989, p. 87 apud GARCIA, (1999, p.23).

Para Tardif (2014), Marx já havia enunciado, que toda práxis social é, de certa forma, um trabalho cujo processo de realização desencadeia uma transformação real no trabalhador, pois para ele, trabalhar não é só transformar um objeto ou situação numa outra coisa, é, sobretudo, transformar a si mesmo no e pelo trabalho, neste caso, no trabalho docente. "Enriquece seu pensamento lembrando o provérbio que diz, a vida é breve, a arte é longa” (TARDIF, 2014, p.57).

Para os docentes e para os acadêmicos da universidade em formação e, para os militantes dos movimentos sociais em seus diferentes afazeres, o tempo de aprendizagem no projeto confundiu-se, por vezes, com o tempo de vida. O trabalho vivido e sentido foi apreendido através de imersões no ambiente social e familiar, no contato direto e cotidiano com as tarefas dos jovens e adultos para cuja realização do projeto houve a formação pouco a pouco.

A metodologia contou com vários momentos que, em dialeticidade desenvolveu-se da seguinte forma: reunião com as lideranças que participaram do projeto; mobilização e sensibilização através de anúncios em rádios, voz comunitária; seleção dos mediadores de leitura; formação dos mediadores de leitura mediante os seguintes conteúdos; sensibilização para a importância da leitura; trabalhando a concepção de leitura numa perspectiva transformadora da realidade; objetivos da leitura; tipologia textual e suas características; estratégias para a compreensão leitora antes, durante e depois da leitura e oficinas de leitura.

Duas vezes por semana, os mediadores de leitura realizaram um trabalho itinerante, visitando as casas dos alfabetizados ou seus pontos de convivência, para desenvolverem as rodas de histórias. Os integrantes puderam escolher dentre os livros, sempre dispostos em um recipiente confeccionado pelas artesãs chamado paneiro, por isso, o nome Paneiroteca, qual o conto a ser trabalhado. Portanto, o tipo de história a ser contada pelos mediadores era definido em situações de movimento entre os leitores e o texto. No desenvolvimento da ação, os mediadores ativavam os conhecimentos prévios do grupo, verificando quais os seus conhecimentos sobre o texto eleito e quais as relações que seriam capazes de fazer ampliando o poder da escuta e da síntese. O passo seguinte foi levá-los a estabelecer previsões, promovendo situações com possibilidades de inferências ou predições sobre o texto. Quando inquiridos demonstravam intimidade com suas práticas e, não só sobre o tema lido. 
A integração da comunidade local foi promovida com a culminância das atividades programadas ao longo do mês. Nesses encontros foram oportunizados momentos para a socialização das histórias ouvidas e discutidas, bem como a relação dos textos com sua leitura de mundo. Puderamse perceber, formas diversificadas de apresentações como, danças, cantorias, teatros e performances poéticas.

O registro escrito, oral, fotográfico e audiovisual das atividades realizadas durante o desenvolvimento do projeto, se constituiu como material que foi utilizado para exposição de uma mostra de extensão em cumprimento às exigências da instituição promotora da ação, bem com o relatório final com a sistematização dos resultados. Por fim, a elaboração e planejamento de um relatório, para o Centro de Referência, Documentação e Memória da Educação de Jovens e Adultos na Amazônia.

Nessa perspectiva, o projeto desenvolveu formações que permitiram aos sujeitos adquirirem as ferramentas necessárias para viverem no contexto de uma sociedade letrada. Analogamente, Fiori (1987) reflete que o sujeito em processo de educação para transformação "Não se deverá aprisionar nos mecanismos de composição vocabular. E buscará novas palavras, não para coleciona-las na memória, mas para dizer e escrever seu mundo, o seu pensamento, para contar sua história. Pensar o mundo é julgá-lo" (FIORI, 1987, p. 7). Foi necessário exercitar os movimentos de codificação e decodificação concomitantemente ao desenvolvimento da leitura, percebendo os usos e características da linguagem nos diversos contextos comunicativos dos diferentes grupos atendidos. Com esse movimento, os mediadores possibilitaram ao leitor processar ativamente a informação, extraindo aspectos relevantes e excluindo o que considerar secundário.

\section{TEMPOS E ESPAÇOS DA AÇÃO FORMATIVA E DE LEITURA}

O projeto foi desenvolvido nos locais de maior referência de cada coletivo, por exemplo, o coletivo de mulheres artesãs ocorreu no terreiro onde cultuam religião de matriz africana em um bairro de Manaus. Os encontros aconteciam aos sábados à tarde e agregaram outros integrantes, seus familiares. Os mediadores de leitura foram os acadêmicos e professoras do curso de Pedagogia de uma instituição do ensino superior e alfabetizadores egressos dos projetos de alfabetização do estado, selecionados e capacitados, contemplando as estratégias de fomento e compreensão de leitura. Após a formação, esses mediadores realizaram junto aos alfabetizados e familiares, um trabalho itinerante de leitura e de histórias de vida concretizando as sugestões que surgiam no processo de desenvolvimento do projeto. 
A promoção desses conhecimentos à população e sua articulação com a comunidade ex terna tem sido uma marca da instituição fazendo com que esta interação resulte em retorno à pesquisa e ao ensino, numa permanente prática de autorreflexão acadêmica bem como em serviços à sociedade. Essas atividades, no entanto, por si só não são suficientes para justificar a existência da academia na sociedade atual. As instituições acadêmicas, especialmente as universidades públicas, com suas finalidades de ensino, pesquisa e extensão, que não se confundem com a tarefa de executoras de políticas públicas, devem possuir um compromisso político com o seu tempo e, portanto, não podem ficar de fora desse campo.

Assim, o projeto se constitui num instrumento social capaz de contribuir para a luta contra as desigualdades sociais. Não se tratou, como dito, de desnaturalizar as funções acadêmico-científicas reduzindo-os a um papel pragmático de operador de políticas públicas, contudo, cuidou de dar um sentido e uma razão maior às suas existências.

\title{
CARACTERIZAÇÃO DOS ATORES
}

Percebeu-se, logo de início, que o olhar sobre os grupos integrantes do projeto, muito diz acerca dos escritos literários. Pontua Rios (2009) que:

\begin{abstract}
Se houve no primeiro contato entre europeus e ameríndios, por meio da operação narcísica do descobridor, uma tendência a desconsiderar a cultura do outro e a querer dobrá-la, torná-la mais do mesmo aventureiro, por sua vez, a nova onda de emigração encabeçada pelas nações europeias que dispersaram pelo mundo "seus pobres para que se tornassem ricos (ou menos pobres) algures" exposto no romance de Ferreira de Castro, deixa entrever o desejo de aniquilar a cultura do outro, dando continuidade ao processo histórico (e narcísico) de anular a cultura alheia. Isso se deve, em parte, ao fato de não se perceber a cultura do outro como valorativa e de julgar a sua própria como sempre superior às demais. (RIOS, 2009, p. 91)
\end{abstract}

Os grupos ricos de culturas envolvidos foram: Mulheres Artesãs e de Terreiro, indígenas do município de Manacapuru e comunitários urbanos do Mauazinho localizado nos arredores do Polo Industrial de Manaus/PIM. Todos com características de letramento reduzidas, mas com distintas e ricas culturas potencializando sobremaneira a troca de saberes. Os mediadores foram acadêmicos e professores do curso de Pedagogia e lideranças dos atores sociais. A cada dia os mediadores se surpreendiam com a estreita relação entre a literatura e o contexto dos grupos. 
As formações ofereceram aos sujeitos um mergulho no mundo da escrita, possibilitando uma compreensão sobre a ampla variedade de textos existentes oportunizando a exploração de inúmeras possibilidades de conhecerem o mundo, mediante a vivência de atividades de leitura e escrita. Assim sendo, para contribuir efetivamente na formação de sujeitos letrados foi imprescindível a ampliação de situações de contato com os textos que circulam socialmente. Essa intimidade com a leitura permitiu que compreendessem como e por que os textos são produzidos, sendo capazes depois de escrevê-los e reescrevê-los.

A leitura é um processo interno, porém indispensável para que se formem leitores e escritores reais. Essas atividades possibilitaram o desenvolvimento não só das habilidades de análise e síntese como, das interpretações e inferências estabelecidas contribuindo assim, para o pensamento crítico, indispensável ao pleno exercício da cidadania.

Aquilo que Torres (2011), p. 44) reflete sobre os novos movimentos sociais se aplica a esses grupos, como se pode a seguir: "Enquanto a arma dos antigos movimentos sociais era a greve de trabalho, os novos movimentos sociais ocupam espaços, ruas, praças e quadras. Eles fazem sua presença e conflitos visíveis nas cidades" (TORRES 2011, p. 44).

Radicaliza o autor ao afirmar que:

Chegou a hora de tomar os novos movimentos sociais seriamente. Em caso afirmativo, a educação de adultos pode tornar-se uma arma poderosa para o empoderamento das pessoas e das comunidades em todo o globo. Do contrário, a educação de adultos e a educação continuada vão continuar a dançar no convés do Titanic (TORRES, 2011, p.55).

A cada leitura, os mediadores davam continuidade às estratégias de forma compartilhada, esclarecendo possíveis dúvidas e resumindo as ideias do texto.

Finalizada a formação com a ação de "contação" de histórias, os atores estabeleciam relações de sua vivência com o tema, ideias principais e detalhes secundários, aprendendo a resumir e isso implicava em omitir o que consideravam secundários e redundantes. O exercício de selecionar o que era importante se constituiu numa maneira de integrar as novas informações de maneira lógica e coesa. As formas de vincular a experiência nutrida da cultura local com a cultura objetivada mais universal exigem um processo de pesquisa permanente na prática, em que não é fácil manter o equilíbrio entre aquilo que é local e aquilo que é universal. Feldmann (2003) aborda esse tema explicitando que: 


\begin{abstract}
Vivemos um tempo de incertezas, em que as coisas acontecem e se transformam muito rapidamente. O tempo parece ter adquirido novas dimensões, há uma pressão muito forte para mudança. Nesse processo de instabilidade geral é comum o desencadear de movimentos de deslegitimação de instituições, poderes papéis sociais e do próprio conhecimento, proporcionando uma desqualificação do saber docente e das escolas. Esses problemas implicam percepções e ações que dificultam a construção de uma educação mais justa e democrática (FELDMANN, 2003, p. 149).
\end{abstract}

Os sujeitos do projeto adquiriram uma nova maneira de interagir com a literatura regional de forma oral e escrita. Essa iniciativa mobilizou o imaginário dos grupos, incentivando novas experiências e expectativas. É imperativo afirmar que a experiência ampliou sua leitura de mundo popularizando, de alguma forma, o acesso e troca de saberes que até então era privilégio de poucos.

\title{
CONSIDERAÇÕES FINAIS
}

Conseguimos observar que a utilização da literatura do e no cotidiano, os neoleitores adquiriram uma nova maneira de interagir com a cultura oral e escrita. Esta iniciativa mobilizou o imaginário dos alunos, incentivando novas experiências e expectativas. O acesso a obras literárias promoveu uma viagem de saberes, exercitando ainda a leitura, a escrita e o reconhecimento de diversas lentes para ler e interpretar a realidade. Freire (1981) alude à sociedade como cambiante e contraditória que denominou de sociedade em "partejamento" porque apresentava e ainda apresenta violentos embates entre um tempo que se esvaziava, com seus valores e que pretendia se preservar e outro que estava por vir buscando configurar-se. Esta analogia se aplica ao projeto executado, e, por isso, reafirma-se que: "Este esforço não nasceu por acaso. Foi uma tentativa de resposta aos desafios contidos nesta passagem que fazia a sociedade" (FREIRE, 1981, p. 35).

A prática da leitura se mostra como possibilidade de ser trabalhada como uma das ferramentas para a prática da liberdade e da diminuição das desigualdades. O acesso aos bens culturais é direito de todos e dever do Estado da mesma forma como, moradia, saúde, trabalho, educação e justiça. Portanto, o desenvolvimento dessa experiência com oficinas contribuiu para ampliar a compreensão desses direitos. É imperativo afirmar que as oficinas ampliaram a leitura de mundo dos sujeitos, popularizando, de alguma forma, o acesso a obras que até então eram restritas a poucos. A dinamização de espaços públicos de fomento à leitura que promovessem formas diversificadas de encontros, grupos de discussão, saraus, performances poéticas, rodas literárias, murais, oficinas de produção literária e cantorias. 
Acredita-se que o projeto foi um passo a mais na luta, para que a educação seja, de fato, um direito de todos na perspectiva de liberdade e de transformação social, bem como se mostrou como possibilidade de um estreitamento de vínculos entre a universidade e os movimentos sociais.

\section{REFERÊNCIAS}

BACELLAR, Luiz Franco de Sá. Sol de Feira. Quatro ed. Manaus: Valer, 2009.

Rondel do Tucumã. In:. Sol de Feira. Disponível em:

<http://www.saraiva.com.br/sol-de-feira-2639058.htm1>. Acesso em: 6 out..2015.

BAUMAN, Zygmunt. Ensaios sobre conceito de cultura. Rio de Janeiro: Zahar, 2012.

CALDART, Roseli Salete ET al. (org.). Dicionário da Educação do Campo. 2. ed. Rio de Janeiro, São Paulo: Escola Politécnica de Saúde Joaquim Venâncio, Expressão Popular, 2012.

FELDMANN, Marina Graziela. Questões Contemporâneas: Mundo do Trabalho e Democratização do Conhecimento. IN: SEVERINO, Antonio Joaquim \& FAZENDA, Ivani Catarina Arantes (Orgs). Políticas Educacionais em Questão. Campinas/SP: Papirus, 2003.

Formação de Professores e Escola na Contemporaneidade. São Paulo: SENAC, 2009.

FIORI, Ernani Maria. Prefácio. In. FREIRE, Paulo. Pedagogia do Oprimido. 17 ed. Rio de Janeiro: Paz e Terra, 1987.

FREIRE, Paulo. Ação Cultural para Liberdade. 5. ed. Rio de Janeiro: Paz e Terra, 1981.

Educação como Prática de Liberdade. 38 ed. São Paulo: Paz e Terra, 2014.

GARCIA, Carlos Marcelo. Formação de Professores: para uma mudança educativa. Porto: Porto , 1999.

MELLO, Thiago. Os Estatutos do Homem. Edição Especial. Manaus: Valer, 2009.

Os Estatutos do Homem. Disponível em: <http://www.revistas.usp.br/comueduc/article/view/36944

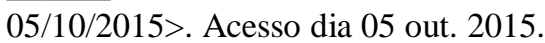

RIOS, Otávio. O outro lugar: Os viajantes descobrem o Paraíso. IN: RIOS, Otávio (Org.). O Amazonas deságua no Tejo: ensaios literários. Edições Eletrônicas. Manaus: UEA Edições, 2009. Disponível em: <http://www.pos.uea.edu.br/data/area/download/download/73-1.pdf.> Acesso 07 out. 2015.

SANTELLI, Adriana Delgado. As estações da Caligrafia de Deus. Revista Eletrônica Seringal de Ideias, ed. Um). Disponível em: <http://www.ufac.br/portal/unidades-administrativas/orgaoscomplementares/edufac/revistaseletronicas/revista-seringal-de-ideias/edicoes/edicao-01-2008/artigos/as-estacoesdacaligrafia-de-deus>. Acesso em 28 jun. 2014.

SILVA, Maria de Nazaré Corrêa. Programa Literatura para Todos. Uma Experiência de Literatura na Amazônia. UEA, 2012.

SILVA, Maria de Nazaré Correa. PANEIROTECA-Projeto de Fomento a Leitura para Neo Leitores na Amazônia. In: Anais II SEEJA-Entrelaçando Olhares Por uma Educação Planetária. Rio de Janeiro: Anais NEAD/PUC-RIO, 2014.

SOUZA, Márcio. A caligrafia de Deus. 3. ed. Manaus: Valer, 2008.

TARDIF, Maurice. Saberes Docentes e Formação Profissional. 17. ed. Petrópolis: Vozes, 2014.

TORRES, Carlos Alberto. Dançando no Convés do Titanic: A Educação de Adultos, O Estado-Nação, e os Novos Movimentos Sociais. In:. JEZINE, Edineide ;TEODORO, Antonio (Org.). Movimentos Sociais e Educação de Adultos na Ibero-América: Lutas e Desafios. Brasília: Líber Livros. 


\section{FORMAÇÃO DE LEITORES NO AMAZONAS: A RELAÇÃO ENTRE UNIVERSIDADE E MOVIMENTOS SOCIAIS} RESUMO

Este artigo se propõe analisar uma experiência realizada por uma instituição de ensino superior do Amazonas nos anos de 2012 e 2013 desenvolvida por meio de um projeto de extensão envolvendo a prática de leitura e literatura com um grupo de mulheres artesãs e índios aldeados. A literatura escolhida foi A Caligrafia de Deus de Marcio Souza (2008), Sol de Feira de Luiz Bacellar (2009) e Os Estatutos do Homem de Thiago de Melo (2009). Os resultados observados nos permitem afirmar que a experiência possibilitou a ampliação da leitura de mundo dos sujeitos, popularizando, o acesso a obras que, até então, eram restritas a poucos, bem como se mostrou como possiblidade de estreitar os vínculos entre a universidade e os movimentos sociais.

Palavras-Chave: Formação de leitores. Movimentos Sociais. Leitura.

\section{READER'S EDUCATIONAL IN THE AMAZON: THE RELATIONSHIP BETWEEN UNIVERSITY AND SOCIAL MOVEMENTS}

ABSTRACT

This article proposes to analyze an experience carried out by an institution of higher education of the Amazon in the years of 2012 and 2013 developed through an extension project involving the practice of reading and literature with a group of women artisans and village Indians. . The chosen literature was The Calligraphy of God by Marcio Souza (2008), Sol de Feira by Luiz Bacellar (2009) and The Statutes of Man by Thiago de Melo (2009). The observed results allow us to affirm that the experience allowed the broadening of the world reading of the subjects, popularizing, access to works that until then were restricted to few, as well as showed as a possibility to strengthen the bonds between the university and the social movements.

Keywoards: reader 's educational. Social movements. Reading.

\section{FORMACIÓN DE LECTORES EN LAS AMAZONAS: LA RELACIÓN ENTRE LA UNIVERSIDAD Y MOVIOS SOCIALES}

Este artículo se propone analizar una experiencia realizada por una institución de enseñanza superior del Amazonas en los años 2012 y 2013 desarrollada por medio de un proyecto de extensión involucrando la práctica de lectura y literatura con un grupo de mujeres artesanas e indios aldeados. . La literatura elegida fue La Caligrafía de Dios de Marcio Souza (2008), Sol de Feria de Luiz Bacellar (2009) y Los Estatutos del Hombre de Thiago de Melo (2009). Los resultados observados nos permiten afirmar que la experiencia posibilitó la ampliación de la lectura de mundo de los sujetos, popularizando, el acceso a obras que, hasta entonces, eran restringidas a pocos, así como se mostró como posibilidad de estrechar los vínculos entre la universidad y los los movimientos sociales.

Palavras clave: Formación de lectores. Movimientos sociales. Lectura. 